Original article

\title{
Comparison of the effects of cryotherapy and placebo on reducing the pain of arteriovenous fistula cannulation among hemodialysis patients: A randomized control trial
}

\author{
Ali Aghajanloo ${ }^{1,2}$, Mansour Ghafourifard ${ }^{3, *}$, Hamidreza Haririan $^{4}$, Parvin Shiri Gheydari $^{2}$
}

(Received: 28 Nov 2015; Accepted: 1 Feb 2016)

\begin{abstract}
Background and Purpose: Pain perception with arteriovenous fistula (AVF) cannulation is a major concern among patients undergoing hemodialysis. This study aimed to compare the efficacy of cryotherapy and placebo in the reduction of AVF puncture-related pain in hemodialysis patients.

Methods: This randomized clinical trial was conducted on 50 patients undergoing hemodialysis selected via random sampling. Patients were randomly divided into two groups of intervention and control. Patients in the intervention group received cryotherapy using ice cubes wrapped in latex gloves, which were placed on the back of the hands without AVF (between the index finger and thumb). The same process was performed on the patients of the control group by using wooden cubes as placebo instead of ice cubes. Pain perception of the patients was recorded during two consecutive hemodialysis sessions using a visual analogue scale. Data analysis was performed in SPSS V.13 using Chi-square and independent T-test.

Results: With cryotherapy, scores of AVF puncture-related pain significantly reduced from $5.9 \pm 0.96$ in session one (routine care) to $3.2 \pm 1.71$ in session two of hemodialysis. However, no significant difference was observed between the two sessions in patients of the control group $(\mathrm{P}=0.07)$.

Conclusion: According to the results of this study, cryotherapy, as a non-pharmacological and complementary approach, could be effective in the prevention of the pain associated with AVF cannulation. Therefore, it is recommended that nurses apply this method before AVF cannulation in order to alleviate pain intensity in hemodialysis patients.
\end{abstract}

Keywords: Arteriovenous fistula, Complementary, Cryotherapy, Hemodialysis, Pain

\section{Introduction}

Hemodialysis is the most common modality used for patients with end-stage renal disease (ESRD) (13 ). Vascular access is required for all the patients who undergo hemodialysis and is considered as a life-saving procedure for these patients (4). Arteriovenous fistula (AVF) is the most common mode of vascular access for patients on maintenance hemodialysis $(5,6)$. However, the pain associated with AVF cannulation remains a major concern among hemodialysis patients (7).

Patients undergoing hemodialysis may frequently experience pain, which is caused by approximately 320 punctures inserted in their AVF each year (8). Moreover, large-gauge needles are normally inserted into the AVF in order to preserve the extracorporeal rate of blood flow at $300 \mathrm{ml} / \mathrm{min}$, which could dramatically increase pain intensity (9-11). Repeated AVF puncturing may lead to adverse

\footnotetext{
${ }^{1}$ Department of Medical Surgical Nursing, School of Nursing and Midwifery, Tehran University of Medical Sciences, Tehran, Iran

${ }^{2}$ Department of Nursing, School of Nursing and Midwifery, Zanjan University of Medical Sciences, Zanjan, Iran

3,* Corresponding author: Department of Medical Surgical Nursing, Faculty of Nursing and Midwifery, Tabriz University of Medical Sciences, Tabriz, Iran. Email: m.ghafori@yahoo.com

${ }^{4}$ Department of Medical Surgical Nursing, Faculty of Nursing and Midwifery, Tabriz University of Medical Sciences, Tabriz, Iran
} 
outcomes such as anxiety, fear and intense pain (8). Furthermore, it could have negative effects on the quality of life of the patients undergoing hemodialysis (12).

Pain perception during fistula needle insertion remains an uncontrolled concern for hemodialysis patients and is considered as one of the most important causes of treatment rejection among ESRD patients (9). AVF puncture-related pain is a highly prevalent complication in patients on hemodialysis (13). In the literature, variable prevalence rates have been reported for AVF puncture-related pain among hemodialysis patients. For instance, Gulperi et al. estimated this rate at $57.5 \%$ (11), while Béfa Noto Kadou reported the rate to be $60.9 \%$ (13). Therefore, pain control during AVF needling should be prioritized in dialysis care (13).

Nurses implement different strategies to alleviate pain in hemodialysis patients during AVF cannulation (8). Previous studies have adopted several methods in this regard, including the use of intradermal lidocaine, buttonhole technique (1416), modified buttonhole cannulation technique (17), EMLA cream (11), ethyl chloride spray (18), and programmed distraction (19). However, some of these strategies are suspected to have negative effects on the function of AVF and could not be used for all patients (8). For instance, in a study conducted in Spain, Pérez-Pérez et al. reported that use of EMLA cream for pain relief in hemodialysis patients prior to AVF cannulation led to allergic reactions and skin rashes (20). In another study performed in Turkey, Çelik et al. claimed that the absorption of topically administered medications in hemodialysis patients was likely to decrease due to some epidermal barriers in the skin (11). In this regard, Page and Taylor reported that the use of topical lidocaine increased vein visibility and increased cannulation difficulty (21).

In a recent study, Bagheri-Nesami (2014) investigated the effect of lavender aromatherapy on the intensity of pain during AVF cannulation (22). According to the results, this complementary method could effectively reduce AVF cannulationrelated pain in the patients. However, preparation and use of this herbal essence for aromatherapy may not be possible in all dialysis centers.

Today, use of non-pharmacological interventions and complementary therapies for pain relief is on the rise $(23,24)$. Cutaneous stimulation is a simple method of pain relief, which is practiced by nurses in order to minimize pain intensity in hemodialysis patients (25). Cryotherapy is a non-invasive approach, which could be simultaneously applied with cutaneous stimulation to the energy meridian of the large intestine in order to enhance the efficacy of cutaneous stimulation in pain management (26). This meridian is located on the back of the hands (between the thumb and forefinger) and is used to relive the pain of the arms, hands, and shoulders (27). Since the forearm and upper arm are the preferred sites for AVF (6), cryotherapy could effectively reduce the pain perception of patients during AVF cannulation. This study aimed to evaluate the effect of cryotherapy on AVF puncture-related pain in patients undergoing hemodialysis.

\section{Materials and Methods}

This clinical trial was conducted at the Hemodialysis Unit of Valiasr Hospital affiliated to Zanjan University of Medical Sciences in Zanjan, Iran during June 2013-August 2014.

Inclusion criteria of the study were as follows: 1) patients undergoing conventional hemodialysis three times a week; 2) dialysis duration of more than three months; 3) healthy AVF access with good function and 4) willingness to participate in the study. Exclusion criteria were the presence of hepatic or cardiac failure, peripheral vasculopathy, active bleeding, dysfunctional fistula, and deep venous thrombosis, and patients who had used painkillers within three hours before hemodialysis were also excluded from the study $(11,22)$.

Sample size of the study was calculated based on the mean of pain scores in control and intervention groups ( $1.77 \pm 1.49$ and $0.97 \pm 0.99$, respectively) in the previous study (28) and considering (95\% confidence interval [CI], $80 \%$ test power). In total, 20 patients were allocated to each study group, and by considering the potential dropout rate, the final sample size was determined at 25 patients per group. 


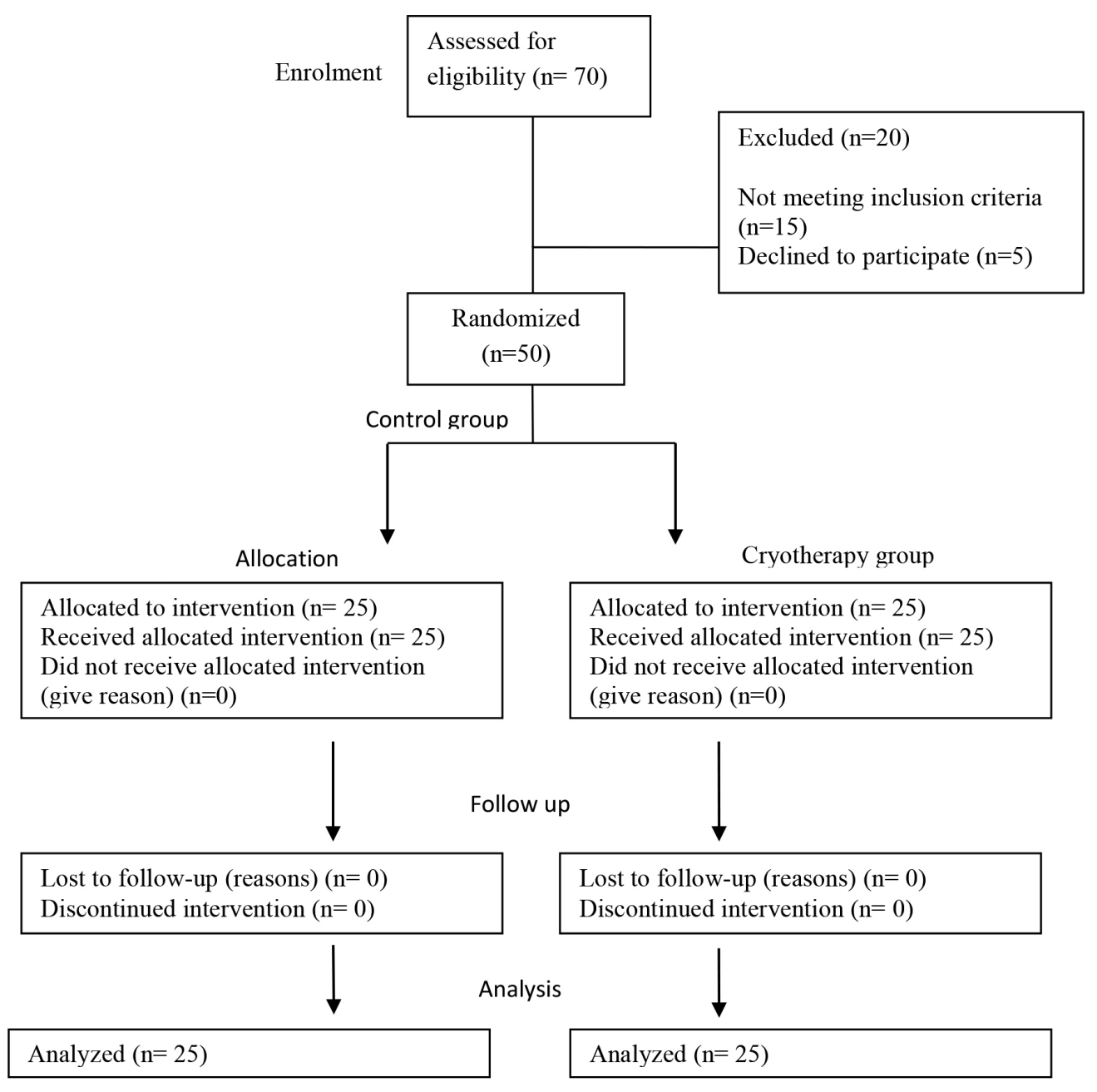

Figure 1. Consort flow chart.

During the time of the study, 105 patients were receiving hemodialysis in Valiasr Hospital, and 70 patients who met the inclusion criteria were enrolled in this study. In total, 50 patients were randomly selected and divided into two groups of intervention $(\mathrm{n}=25)$ and control $(\mathrm{n}=25)$.

In this study, as proposed by Sabitha et al. (27), cryotherapy procedure was used without placebo. For better comparison, patients were randomly allocated to experimental and placebo groups. Pain perception of the patients was recorded during two consecutive sessions of hemodialysis. On the first session, patients in each group received routine dialysis treatment without any interventions before AVF cannulation, and rate of AVF cannulationrelated pain was determined as well.

On the second session, patients in the intervention group received cryotherapy by using ice cubes wrapped in latex gloves, which were placed on the web between the index finger and thumb of the hand without AVF (i.e., contralateral arm) (27). This process initiated 10 minutes before cannulation and continued throughout the needling procedure (approximately three minutes). The same procedure was repeated for the control subjects, and wooden cubes were used as placebo instead of ice cubes (Figure 1).

Size of the ice and wooden cubes was similar, and they were both wrapped in brown latex gloves. The intervention was performed by two trained nurses; as the ice or wooden cubes were placed on the hand of the patient by one nurse, the other nurse implemented AVF cannulation. None of the patients in the study groups was aware of the group 
assignments.

A visual analogue scale was used to measure the intensity of needling pain immediately after AVF cannulation. This scale was composed of a $10-\mathrm{mm}$ horizontal line ranging from zero (no pain) to 10 (absolutely painful) (29). Moreover, demographics data of the patients were collected in prepared checklists, including age, gender, education status, and site of AVF.

Study protocol of this clinical trial was approved by the Ethics Committee of Zanjan University of Medical Sciences. Objectives of the study were explained to the participants, and written informed consent was obtained from all the patients prior to the study. Moreover, participation in the study was voluntary, and patients were assured of confidentiality terms.

Data analysis was performed in SPSS V.13 using independent and paired T-test and Chi-square. In addition, normal distribution of study variables was assessed using the Kolmogorov-Smirnov test, and normally distributed data were presented as mean and standard deviation. In this study, P value of less than 0.05 was considered significant.

\section{Results}

Demographic characteristics of the patients in the intervention and control groups are presented in Table 1. In this study, mean age of the patients in the control and intervention groups was $50.2 \pm 19$ and $56.1 \pm 15$ years, respectively $(\mathrm{P}=0.30)$. Most of

Table 1. Demographic characteristics of hemodialysis patients $(\mathrm{n}=54)$

\begin{tabular}{lccc}
\hline Variables & $\begin{array}{c}\text { Control } \\
\text { Group } \\
(\mathbf{n = 2 5})\end{array}$ & $\begin{array}{c}\text { Cryotherapy } \\
\text { Group } \\
(\mathbf{n = 2 5 )}\end{array}$ & P-value \\
\hline Age (year)* & $50.2 \pm 19$ & $56.1 \pm 15$ & 0.30 \\
\hline Gender (Female/Male) & $10 / 15$ & $12 / 13$ & 0.51 \\
\hline Marital Status (Single/Married) & $8 / 17$ & $5 / 20$ & 0.40 \\
\hline $\begin{array}{l}\text { Education Status } \\
\text { Illiterate }\end{array}$ & 12 & 10 & \\
$\begin{array}{l}\text { Below Diploma } \\
\text { Diploma }\end{array}$ & $\begin{array}{c}6 \\
\text { Academic Education }\end{array}$ & 3 & 0.20 \\
\hline $\begin{array}{l}\text { Duration of Hemodialysis } \\
\text { (months)* }\end{array}$ & $22.8 \pm 14$ & $18.9 \pm 26.9$ & 0.70 \\
\hline $\begin{array}{l}\text { Duration of Arteriovenous Fistula } \\
\text { Use (month)* }\end{array}$ & $22.3 \pm 12.6$ & $20.4 \pm 10.7$ & 0.10 \\
\hline *Values are presented as Mean \pm Standard Deviation & \\
\hline Valum & &
\end{tabular}

*Values are presented as Mean \pm Standard Deviation
Table 2. Comparison of mean pain scores in control and cryotherapy groups

\begin{tabular}{lccc}
\hline Variables & $\begin{array}{c}\text { Control Group } \\
(\mathbf{n = 2 5})\end{array}$ & $\begin{array}{c}\text { Cryotherapy Group } \\
(\mathbf{n = 2 5})\end{array}$ & P \\
\hline Session One & $5.5 \pm 0.82$ & $5.9 \pm 0.96$ & 0.20 \\
\hline Session Two & $5.1 \pm 1.25$ & $3.2 \pm 1.71$ & 0.001 \\
\hline P-value & 0.07 & 0.001 & \\
\hline
\end{tabular}

the patients in the control $(60 \%)$ and intervention groups $(52 \%)$ were male $(\mathrm{P}=0.51)$, and $44 \%$ of the participants were illiterate.

Comparison of some treatment-related variables, such as the duration of hemodialysis and AVF, between the study groups was indicative of no significant difference in this regard $(\mathrm{P}>0.05)$ (Table 1). Patients in both study groups were homogenous in terms of baseline data, which contributed to the controlling of the potential confounding variables.

In this study, scores of AVF puncture-related pain on the first session of hemodialysis, in which the patients received routine care, were similar between the cryotherapy and placebo groups $(\mathrm{P}>0.05)$. As for the second session, use of cryotherapy significantly reduced the scores of AVF puncture-related pain from $5.9 \pm 0.96$ on the first session to $3.2 \pm 1.71$ on the second session $(\mathrm{P}=0.001)$. However, mean scores of AVF puncture pain had no significant difference in the first and second sessions of hemodialysis in the patients of the placebo group $(\mathrm{P}=0.07)$ (Table 2).

\section{Discussion}

In the present study, mean age of the patients in both groups was above 50 years, which is similar to the results of previous studies in this regard $(11,21$, $22)$. According to the literature, advanced age is a major risk factor for the incidence of chronic renal failure $(18,30)$; consequently, mean age of many hemodialysis patients is relatively high.

As determined in the current research, duration of dialysis was similar to previous studies in this regard $(7,19)$. Mean duration of hemodialysis with fistula among the patients in the present study was 20 months, which is in line with the results of previous studies (27). However, this finding was inconsistent with the results obtained by Çelik et al. (11) in Turkey. Accordingly, mean duration of dialysis with fistula 
was almost 48 months, and this difference could be due to variations in study parameters.

Vascular access, such as AVF, is the Achilles heel of dialysis (31), and patients on hemodialysis experience significant pain during AVF cannulation (8). In the present study, we evaluated the efficacy of cryotherapy in alleviating the pain caused by AVF cannulation among the patients undergoing conventional hemodialysis. According to our findings, mean of pain scores was significantly lower in the patients receiving cryotherapy compared to placebo subjects.

In a recent study conducted on 40 children undergoing hemodialysis, Hassan et al. (28) reported that cryotherapy reduced the pain intensity of AVF needling among these children. Therefore, they recommended cryotherapy as a routine care procedure for the management of the pain associated with needle puncture in children on hemodialysis.

Hemodialysis patients experience many complications during the course of their treatment (2, 32-35), and the pain caused by AVF needling is a major concern among these patients (13). In the literature, various recommendations have been proposed with regard to the reduction of AVF cannulation-related pain, including the use of cold compress or warm footbath $(28,36)$. According to the results of the study by Movahedi et al. (36), use of local refrigeration before venipuncture reduced the intensity of venipuncture-related pain.

Today, more patients prefer non-pharmacological treatments due to the cost-efficiency and accessibility (13). Findings of the present study are consistent with the results obtained by Sabitha et al. (27), which indicated that application of cold compress by placing ice cubes between the index finger and thumb of the hands significantly reduced pain scores among hemodialysis patients.

In another study conducted on 41 dialysis patients, Çelik et al. (11) evaluated the effect of topical vapocoolant spray on the pain caused by venipuncture. They reported that ethyl chloride vapocoolant was as effective as EMLA cream in the prevention of puncture pain in patients undergoing hemodialysis. Rapid evaporation of vapocoolant liquid spray from the skin surface decreases the temperature of skin leading to the short-term interruption of the pain sensation. This process probably occurs through the desensitization of pain receptors and affecting the ion channels involved in the transmission of pain (11).

It is noteworthy that vapocoolant or EMLA cream take effect within 45-60 minutes to relieve pain (11), while cryotherapy with ice cubes takes only 10 minutes to exert its analgesic effect. Furthermore, cryotherapy is inexpensive and easily implemented, which makes this method a suitable option for nurses in the management of the pain caused by vascular access needling. On the other hand, since vapocoolant, EMLA cream and other analgesics are applied to the hand of the patients with AVF, side effects such as pruritus, erythema, and skin rash on the cannulation site are expected to occur (21). Based on the methods used in previous studies (27), we performed cryotherapy on the hand without AVF (i.e., contralateral arm), which led to no side effects on the cannulation site.

According to the literature, variations in demographic features may affect pain perception. In this regard, the results of one study indicated that the intensity of AVF puncture-related pain had a significant correlation with female gender, while in the current study, no significant relationship was observed between the duration of AVF, education status, and age of the participants (27). In other studies in this regard, pain intensity has been reported to have significant associations with old age, female gender, and smoking habits $(37,38)$. However, these findings are inconsistent with the results of the present study. In this regard, our findings are in line with the study by Çelik et al. (11), which reported no significant correlations between pain intensity and factors such as age, gender, and smoking habits.

\section{Conclusion}

According to the results of this study, cannulation technique is essential for inhibiting the risk factors that may compromise vascular access in dialysis patients (39). Furthermore, use of cryotherapy as a non-pharmacological approach was observed to reduce the pain scores associated with AVF cannulation in hemodialysis patients. Therefore, it 
is recommended that nurses apply this technique for the management and alleviation of the pain caused by AVF cannulation.

\section{Conflicts of interest}

None declared.

\section{Authors' contributions}

M Ghafourifard was the chief investigator and principal author of the manuscript. H Haririan was the research assistant. A Aghajanloo contributed to study conception and design, and made the necessary coordinations. A Aghajanloo and M Ghafourifard were the chief investigators. A Aghajanloo, PS Gheydari, and $\mathrm{H}$ Haririan collected the data. A Aghajanloo and $M$ Ghafourifard analyzed the data. A Aghajanloo, H Haririan, and PS Gheydari reviewed the literature.

\section{Acknowledgements}

Hereby, we extend our gratitude to the Research Deputy of Zanjan University of Medical Sciences for the financial support of this study.

\section{References}

1. Shahgholian N, Ghafourifard M, Shafiei F. The effect of sodium and ultra filtration profile combination and cold dialysate on hypotension during hemodialysis and its symptoms. Iran J Nurs Midwifery Res 2011; 16(3):212-6.

2. Ghafourifard M, Rafieian M, Shahgholian N, Mortazavi M. Effect of linear and stepwise sodium and ultra filtration profiles on intradialytic hypotension and muscle cramps in renal disease patients. J Shahrekord Univ Med Sci 2010; 12(3):22-8.

3. Shahgholian N, Ghafourifard M, Rafieian M, Mortazavi M. Impact of two types of sodium and ultra filtration profiles on Intradialytic hypotension in hemodialysis patients. Iran J Nurs Midwifery Res 2009; 13(4):135-9.

4. Kumbar L. Complications of arteriovenous fistulae: beyond venous stenosis. Adv Chronic Kidney Dis 2012; 19(3):195-201.

5. Allon M, Robbin ML, Umphrey HR, Young CJ, Deierhoi MH,
Goodman J, et al. Preoperative arterial microcalcification and clinical outcomes of arteriovenous fistulas for hemodialysis. Am J Kidney Dis 2015; 66(1):84-90.

6. Srivastava A, Sharma S. Hemodialysis vascular access options after failed Brescia-Cimino arteriovenous fistula. Indian J Urol 2011; 27(2):163-8.

7. Azimian J, Abbasali Madadi Z, Falahatpishe F, Alipour Heidari M. Effect of warm footbath on arteriovenous fistula puncture-related pain in dialysis patients. J Qazvin Univ Med Sci 2015; 18(6):39-45.

8. Figueiredo AE, Viegas A, Monteiro M, Poli-de-Figueiredo CE. Research into pain perception with arteriovenous fistula (avf) cannulation. J Ren Care 2008; 34(4):169-72.

9. Crespo Montero R, Rivero Arellano F, Contreras Abad MD, Martinez Gomez A, Fuentes Galan MI. Pain degree and skin damage during arterio-venous fistula puncture. EDTNA ERCA J 2004; 30(4):208-12.

10. Quinn RR, Lamping DL, Lok CE, Meyer RA, Hiller JA, Lee J, et al. The Vascular Access Questionnaire: assessing patient-reported views of vascular access. J Vasc Access 2007; 9(2):122-8.

11. Çelik G, Özbek O, Yılmaz M, Duman I, Özbek S, Apiliogullari S. Vapocoolant spray vs lidocaine/prilocaine cream for reducing the pain of venipuncture in hemodialysis patients: a randomized, placebo-controlled, crossover study. Int J Med Sci 2011; 8(7):623-7.

12. Gong L, Liu J, Yan J, Wang L. Effect of puncture-related pain on the quality of life in patients undergoing maintenance hemodialysis through internal arteriovenous fistula. Zhong Nan Da Xue Xue Bao Yi Xue Ban 2014; 39(12):1292-8.

13. Béfa Noto Kadou K, Kossi Akomola S, Eyram Yoan Makafui A, Ghislain I, Jacques B, Claude Mawufemo T, et al. Pain during arterio-venous fistula (AVF) cannulation. Am J Int Med 2014; 2(5):87-9.

14. Ball LK. The buttonhole technique for arteriovenous fistula cannulation. Nephrol Nurs J 2006; 33(3):299-304.

15. Verhallen AM, Kooistra MP, van Jaarsveld BC. Cannulating in haemodialysis: rope-ladder or buttonhole technique? Nephrol Dial Transplant 2007; 22(9):2601-4.

16. Vaux E, King J, Lloyd S, Moore J, Bailey L, Reading I, et al. Effect of buttonhole cannulation with a polycarbonate PEG on in-center hemodialysis fistula outcomes: a randomized controlled trial. Am J Kidney Dis 2013; 62(1):81-8.

17. Marticorena RM, Hunter J, Macleod S, Petershofer E, Dacouris N, Donnelly S, et al. The salvage of aneurysmal fistulae utilizing a modified buttonhole cannulation 
technique and multiple cannulators. Hemodial Int 2006; 10(2):193-200.

18. Hogan ME, Smart S, Shah V, Taddio A. A systematic review of vapocoolants for reducing pain from venipuncture and venous cannulation in children and adults. J Emerg Med 2014; 47(6):736-49.

19. Alhani F. The effect of programmed distraction on the pain caused by venipuncture among adolescents on hemodialysis. Pain Manag Nurs 2010; 11(2):85-91.

20. Pérez-Pérez LC, Fernández-Redondo V, Ginarte-Val M, Paredes-Suárez C, Toribio J. Allergic contact dermatitis from EMLA cream in a hemodialyzed patient. Dermatitis 2006; 17(2):85-7.

21. Page D, Taylor DM. Vapocoolant spray vs subcutaneous lidocaine injection for reducing the pain of intravenous cannulation: a randomized, controlled, clinical trial. $\mathrm{Br} \mathrm{J}$ Anaesth 2010; 105(4):519-25.

22. Bagheri-Nesami M, Espahbodi F, Nikkhah A, Shorofi SA, Charati JY. The effects of lavender aromatherapy on pain following needle insertion into a fistula in hemodialysis patients. Complement Ther Clin Pract 2014; 20(1):1-4.

23. Hassett AL, Williams DA. Non-pharmacological treatment of chronic widespread musculoskeletal pain. Best Pract Res Clin Rheumatol 2011; 25(2):299-309.

24. Astin JA. Mind-body therapies for the management of pain. Clin J Pain 2004; 20(1):27-32.

25. Kubsch SM, Neveau T, Vandertie K. Effect of cutaneous stimulation on pain reduction in emergency department patients. Accid Emerg Nurs 2001; 9(3):143-51.

26. Manal EF, Abd El-Hay AH, El-Shikh AA. Cutaneous stimulation: its effect on pain relieving among hemodialysis patients. J Edu Pract 2014; 5(1):9-20.

27. Sabitha PB, Khakha D, Mahajan S, Gupta S, Agarwal M, Yadav S. Effect of cryotherapy on arteriovenous fistula puncture-related pain in hemodialysis patients. Indian J Nephrol 2008; 18(4):155-8.

28. Hassan A, Darwish MM, El-Samman GA, Fadel FI. The impact of cryotherapy on pain intensity at puncture sites of arteriovenous fistula among children undergoing hemodialysis. J Am Sci 2012; 8(12):1490-500.

29. Figueiredo AE, Viegas A, Monteiro M, Poli-de-Figueiredo
CE. Research into pain perception with arteriovenous fistula (avf) cannulation. J Ren Care 2008; 34(4):169-72.

30. Nikeghbalian S, Bananzadeh A, Yarmohammadi $H$. Difficult vascular access in patients with end-stage renal failure. Transplant Proc 2006; 38(5):1265-6.

31. Parisotto MT, Schoder VU, Miriunis C, Grassmann AH, Scatizzi LP, Kaufmann P, et al. Cannulation technique influences arteriovenous fistula and graft survival. Kidney Int 2014; 86(4):790-7.

32. Haririan HR, Aghajanlo A, Ghafurifard M. Evaluation of social support level among hemodialysis patients in the hospitals of Zanjan. Med Sci J Islamic Azad Univ Tehran Med Bran 2013; 23(1):74-80.

33. Aghajanloo A, Ghafouri Fard M. Assessment of informational and instrumental support in hemodialysis patients in the hospitals of Zanjan university of medical sciences, 2011. Prev Care Nurs Midwifery J 2011; 1(1):25-30.

34. Ghafourifard M, Rafieian M, Shahgholian N, Mortazavi M. Effect of sodium dialysate variation in combining with ultra filtration on intradialytic hypotension and intradialytic weight gain for patients on hemodialysis. J Mazand Univ Med Sci 2009; 19(72):19-26.

35. Ghafourifard M, Rafieian M, Shahgholian N, Mortazavi M. Impact of two types of sodium and ultra filtration profiles on systolic and diastolic blood pressure in patients during hemodialysis. Hayat 2010; 16(1):5-12.

36. Movahedi AF, Rostami S, Salsali M, Keikhaee B, Moradi A. Effect of local refrigeration prior to venipuncture on pain related responses in school age children. AustJ Adv Nurs 2006; 24(2):51-5.

37. Hooten WM, Shi Y, Gazelka HM, Warner DO. The effects of depression and smoking on pain severity and opioid use in patients with chronic pain. Pain 2011; 152(1):223-9.

38. Parruti G, Tontodonati M, Rebuzzi C, Polilli E, Sozio F, Consorte A, et al. Predictors of pain intensity and persistence in a prospective Italian cohort of patients with herpes zoster: relevance of smoking, trauma and antiviral therapy. BMC Med 2010; 8(1):58-68.

39. Vale E, Lopez-Vargas P, Polkinghorne K. Nursing care of arteriovenous fistula/arteriovenous graft. Johan Briggs Inst Viitat 2011; 20:2014-37. 